\title{
ESTADO E SOCIEDADE NO BRASIL: uma introdução acerca da influência weberiana no pensamento político brasileiro
}

\author{
Sidney Tanaka de Souza Matos
}

Mestrando em Ciência Política na Universidade Estadual de Campinas.

O presente artigo pretende levantar elementos da análise weberiana que influenciaram o debate acerca da constituição da democracia no Brasil em alguns autores que tiveram a formação e o desenvolvimento do Estado brasileiro como objeto de estudo. Partindo da clássica abordagem de Sérgio Buarque de Holanda em "Raízes do Brasil", o artigo busca ilustrar o panorama da evolução da influência deste pilar das ciências sociais no Brasil.

Palavras-chave: autoritarismo; burocracia; democracia; dominação carismática; patrimonialismo.

\section{A} teoria sociológica de Max Weber constituise em um dos pilares das ciências humanas. Marcada principalmente pela sua preocupação com a racionalidade da ação humana, Weber formula teoricamente, à partir de sua construção dos tiposideais, as formas de dominação política que se desenvolveram ao longo da história humana; relacionando intimamente a democracia moderna com a forma de dominação racionallegal e, por extensão, com a sociedade capitalista moderna, calcada nas formas racionais de sua orientação.

Dentro dessa preocupação com a racionalidade do aparelho estatal dentro de seu conceito de forma de dominação, Weber atribui grande importância ao estudo da burocracia, em especial em sua forma mais desenvolvida, que é na dominação racional-legal, onde esta alcança o ápice de seu poder dentro do aparelho do Estado

Constituindo um importante marco da discussão sobre a democracia no Brasil, a obra "Raízes do Brasil", de Sérgio Buarque de Holanda revolucionou a discussão do tema, deslocando o debate das questões étnicas e da preocupação com a constituição de uma identidade nacional até então em voga e presentes em autores como Gilberto Freyre e Oliveira Vianna para o problema da dificuldade de constituição da esfera pública no Brasil.

Nesta obra pode-se perceber uma indisfarçada influência exercida pela teoria Weberiana sobre Holanda. Weber analisa em sua obra "Economia e Sociedade" os tipos de dominação política a partir de suas clássicas definições de dominação - " "...) probabilidade de encontrar obediência para ordens específicas (ou todas) dentro de determinado grupo de pessoas" - e da diretamente relacionada de legitimidade, entendendo-se que esta é o fundamento básico da dominação: "(...) nem o costume ou a situação de interesse, nem os motivos puramente afetivos ou racionais referentes a valores de vinculação poderiam constituir fundamentos confiáveis de uma dominação. Normalmente junta-se a esses fatores outro elemento: a crença na legitimidade ". ${ }^{2}$ Tendo em vista estas definições, Weber constrói os tipos ideais de dominação que servirão de instrumento analítico básico. ${ }^{3}$

Sérgio Buarque de Holanda, em "Raízes do Brasil", utiliza-se dos conceitos de tipos ideais de Weber para definir o Estado brasileiro, detectando uma estrutura estatal de tipo patrimonialista, que se constrói a partir de uma formação sócio-cultural de raízes ibéricas que foi trazida com os colonizadores portugueses. ${ }^{4}$

$\mathrm{O}$ autor identifica como característica desta cultura ibérica implantada no Brasil o culto à personalidade, fruto do individualismo ibérico. Este culto à personalidade leva a uma estrutura social pouco organizada hierarquicamente, composta de instituições e costumes de uma "indolência displicente", que por sua vez tem com consequiência a falta de coesão da vida social.

Outra importante característica da cultura ibérica herdada pelo povo brasileiro é a influência da religião católica, em contraposição a uma cultura protestante nos moldes do calvinismo, o que impossibilitou o desenvolvimento no Brasil de uma cultura racional (nos moldes da conceituação weberiana) e teve como resultado a concentração do elemento de união social na figura do governo: "Nas nações ibéricas, à falta dessa racionalização da vida, que tão cedo ex- 
perimentaram algumas terras protestantes, o princípio unificador foi sempre representado pelos governos. Nelas predominou, incessantemente, o tipo de organização política artificialmente mantida por uma fôrça exterior que, nos tempos modernos, encontrou uma das suas formas características nas ditaduras militares". 6

O não desenvolvimento de uma cultura protestante, nos moldes do calvinismo resultou também no não desenvolvimento de uma forte ética do trabalho - era notório o desprezo ibérico pelo trabalho manual - o que dificultou o surgimento de uma racionalidade capitalista e uma maior capacidade de organização social.

Holanda concede grande importância a influência da vida rural na formação da sociedade brasileira, ao argumentar que era nas propriedades rurais que se concentrava a vida da colônia, influência determinante esta que não terminou com a abolição da escravatura, em 1888. Nesta civilização de raízes rurais, a política era dominada pela aristocracia rural: "Na monarquia eram ainda os fazendeiros escravocratas e eram filhos de fazendeiros, educados nas profissões liberais, quem monopolizava a política, elegendo-se ou fazendo eleger seus candidatos, dominando os parlamentos, os ministérios, em geral todas as posições de mando, e fundando a estabilidade das instituições neste incontestado domínio". 'Somava-se a este domínio econômico o domínio cultural da sociedade patriarcal, resultado do culto ao personalismo, típico das raízes ibéricas.

Esta mentalidade senhorial contaminou toda a vida social, levando a relações políticas de caráter privado e personalista, dificultando a publicização das relações políticas e sociais, que leva ao autoritarismo. Daí a afirmação de Holanda de que "A democracia no Brasil foi sempre um lamentável mal-entendido": a importação de formas de organização política baseadas na experiência dos países democráticos avançados demonstrava-se inconciliável com o patriarcalismo e o personalismo brasileiros, levando a formas liberaldemocráticas em sua aparência, mas de essência aristocrática e autoritária. Assim, como coloca Rezende, há uma tensão entre a organização social e a forma de dominação política. Esta inadequação entre a organização política e social leva ao autoritarismo, não só dos detentores do poder, mas também de seus muitos de seus críticos, como Oliveira Vianna, que defende a formação de um Estado forte que publicizaria as relações sociais em contraposição ao Estado patrimonialista brasileiro, onde as famílias formariam verdadeiros clãs que tomam o aparelho do Estado no sistema liberal brasileiro, perpetuando-as no poder.

Esta situação, que impede a publicização das relações sociais, dificultando a percepção da diferença entre os espaços público e privado é retratada por Holanda na figura do "Homem Cordial". O "Homem Cordial", 8 resultado do tipo de socialização típica da sociedade patriarcal que caracterizou a formação social brasileira é um indivíduo incapaz de conceber a impessoalidade na esfera pública, habituado que está com o convívio social centrado na família, na esfera íntima e, portanto, caracterizada pelo comportamento passional.

Holanda critica também o que ele denominou de "vício do bacharelismo", fruto do culto a personalidade típico da formação social ibérica, visto que a ostentação de um título eleva o status pessoal de seu portador. Outra crítica do autor a intelectualidade nacional é que esta é composta basicamente pelos filhos da aristocracia rural, conservadora e senhorial, que se especializam nas profissões liberais perpetuando o domínio do Estado através da tomada de seu aparelho burocrático e político. Daí a ineficácia do sistema representativo no Brasil; carecendo de sólidas bases sociais, o embate político acaba por converter-se em um jogo de conchavos, o que vem a explicitar a cordialidade no sistema político.

Estabelece-se assim um Estado assentado sobre uma base política oligárquica que tem sua manifestação máxima na "Política dos Governadores", que estabeleceu a hegemonia política dos Partidos Republicanos paulista e mineiro na estrutura do Estado, apoiados pelas oligarquias agrícolas regionais que conseguiam assim fazer prevalecer seus interesses junto ao governo por intermédio de um sistema eleitoral viciado onde, por trás de uma aparência de escolha democrática dos ocupantes de cargos eletivos na estrutura do Estado, desenvolveu-se toda uma máquina de direcionamento do processo eleitoral onde predominavam a fraude e o compromisso coronelista. ${ }^{9}$ O poder do "coronel", por sinal, advém justamente da estrutura rural e patriarcal descrita por Holanda, onde os colonos e pequenos produtores contraem uma ligação de dependência econômica em relação ao dono das terras (o "coronel"), visto que é delas que eles retiram sua subsistência. É, portanto, através desta dependência econômica frente ao "coronel" que os colonos são manipulados, e esta manipulação se traduz em votos para ele e seus candidatos. ${ }^{10}$

Nem mesmo a modernização e urbanização da sociedade brasileira, que possibilitou o aumento do contingente de trabalhadores assalariados e das reivindicações de caráter urbano logrou a publicização das relações Estado-sociedade; como comprova a ascensão ao poder de Getúlio Vargas, um líder de cunho carismático, cujo estilo se encaixava perfeitamente no que Holanda denominou de "culto à personalidade".

Analisando o período pós-Revolução de 1930, Maria do Carmo Campello de Souza utiliza também uma abordagem com grande influência weberiana, ao analisar a progressiva ocupação por agências burocrático-estatais do espaço decisório o organizacional do Estado brasileiro, constituindo uma estrutura estatal francamente centralista. ${ }^{11}$

À partir dessa abordagem, a autora mostra como a intervenção nos Estados dava-se através da articulação entre interventorias e o DASP $^{12}$ (e suas ramificações estaduais —os "daspinhos"), que eram os canais de ligação entre as oligarquias estaduais e o poder central. ${ }^{13}$

Cita também a criação, no plano de coordenação em campos específicos da economia, de variados institutos, autarquias e grupos técnicos, sob direção da Presidência da República.

Cabe ainda citar a reestruturação sindical e a remodelação das Forças Armadas, como elementos que possibilitaram a construção do Estado centralizador do Estado Novo.

Demonstrando a importância do aparato burocrático durante o Estado Novo, Maria do Carmo Campello de Souza mostra que o DASP, através de suas ramificações estaduais (os "daspinhos"), "Funcionavam ao mesmo tempo como 
uma espécie de legislativo estadual e como corpo supervisor para o interventor e o Ministério da Justiça". ${ }^{14}$

As interventorias, o DASP e o Ministério da Justiça atuavam articulados na administração dos Estados. O interventor atuava como coordenação política, enquanto o DASP funcionava como corpo legislativo.

Os institutos, autarquias e grupos técnicos, que nominalmente eram subordinadas ao Presidente da República, na prática, ficavam sob o controle dos ministérios aos quais correspondiam, atuando como agências centralizadoras do poder central para campos específicos, e possuindo papéis e poderes muito variados.

Quanto à estrutura sindical, pode-se afirmar que o Estado passa a controlar as organizações operárias urbanas ao conferir ao Ministério do Trabalho um papel decisivo no reconhecimento e na operação dos sindicatos. A legislação trabalhista, de caráter corporativista cria uma hierarquia de entidades sindicais paralelas e separadas, não permitem a existência de uma confederação geral do trabalho, somente federações estaduais ligadas a várias confederações nacionais. Ao Ministério do Trabalho é ainda dado o direito de intervir unilateralmente nos assuntos internos de qualquer entidade estatal e, conseqüentemente sobre o movimento operário.

A reestruturação das Forças Armadas também desempenhou importante papel no processo de centralização autoritária, à medida que, por um lado, o crescimento do Exército implicou na quebra da autonomia das milícias estaduais; tendo o Exército atuado como "avalista final" da estrutura burocrático estatal getulista; e por outro, atuando através de seus quadros técnicos na implantação de políticas de desenvolvimento industrial.

Nota-se assim a grande importância dada pela autora na instituição de uma estrutura burocrática de dominação através da criação do DASP e dos institutos, autarquias e grupos técnicos, por um lado, e pela burocratização da organização sindical através da criação de uma estrutura corporativa, que visava o controle do movimento operário.

Por sinal, para a autora, dada a inexistência de movimentos de oposição ao Estado Novo com amplas bases sociais, ou capaz de levar a uma confrontação ideológica mais drástica entre as classes sociais, é possível afirmar que a Estrutura política do Estado Novo foi determinante na construção da nova estrutura democrática, configurando-se, assim, uma linha de continuidade entre o Estado Novo e a Democracia Populista, com a sobrevivência da máquina política criada por Vargas, assentada nas interventorias e na burocracia estatal, graças ao importante papel no processo de transição democrática que reservou para si.

Analisando o mesmo período, Bolívar Lamounier atribui-lhe um talhe eminentemente populista e autoritário que, no entanto, exerceu um importante papel na estruturação de uma nova base política que, através da recentralização do Estado, como observa-se acima. ${ }^{15}$

Utilizando a figura de um tripé sobre o qual se assentou o Estado getulista, Lamounier, destaca em primeiro lugar, a transformação da figura do próprio Getúlio em centro de devoção das massas, atribuindo-lhe um em especial à partir de 1935, quando este expediente passa a ser ostensivamente utilizado para a constituição do "empuxo político plebiscitário" com o qual este tentou manter sua posição política, movimento que contou com a ativa contribuição do DIP (Departamento de Imprensa e Propaganda). ${ }^{16}$

Lamounier não confere, porém, à figura de Getúlio a imagem do líder carismático ${ }^{17}$ por excelência. $\mathrm{O}$ autor observa que ele não era depositário previamente da devoção plebiscitária de que gozou após assumir o governo com a Revolução de 1930. Esta devoção foi construída paulatinamente após sua subida ao poder, com a paulatina aceitação das políticas concebidas e implementadas durante o Estado Novo.

O autor lembra que antes mesmo da Revolução de 30 já havia se constituído no plano simbólico um consenso em relação a centralização política e ampliação do setor público como "salvadores da lavoura" em meio a situação de crise do capitalismo herdada do final da década de 20 e com a ascensão do nazi-facismo na Europa (cujo crescimento deve muito a crise dos anos 20).

Nota-se que Getúlio não constituiu, na acepção de Lamounier, o típico líder carismático weberiano, porém, em suas características básicas, permanecem as características básicas da dominação carismática fundamentada psicologicamente em uma confiança pessoal em relação ao líder, fruto da atribuição de qualidades no mínimo extra-cotidianas.

Deve-se ressaltar também a inexistência, em Lamounier, de uma dominação puramente carismática. Ao contrário, o autor dá destaque ao arcabouço institucional construído durante o período getulista, atribuindo a ele e a implementação do seu projeto político um importante na constituição da imagem carismática de Getúlio.

Surge assim um Estado calcado tanto na dominação burocrático-legal quanto na figura carismática de Getúlio Vargas, o que não entra em contradição com a teoria weberiana, pois como tipos-ideais, estas são instrumentos analíticos, não sendo encontradas em suas formas puras.

Analisando o período da ditadura militar, Celso Lafer também se defronta com os problemas colocados por Weber em sua teoria política.

Segundo Lafer, ao assumir o controle do Estado, os militares vêem-se frente ao problema da legitimação de seu poder. $\mathrm{O}$ autor coloca que o Congresso, embora não estivesse organicamente comprometido com o governo Goulart, estava comprometido com o pacto de dominação populista e, ao defender as bases deste pacto e concomitantemente a seu esvaziamento enquanto instância decisória, o Congresso passou a opor-se ao regime, convertendo-se em uma "caixa de ressonância" das queixas da sociedade civil. Dessa forma, observa-se a estruturação de uma estratégia de esvaziamento do Congresso enquanto instância decisória, na medida em que inverte o seu papel na legitimação do uso da moeda da coerção organizada, como demonstra o trecho do texto do AI-1 transcrito abaixo:

"Fica assim, bem claro, que a revolução não procura legitimar-se através do Congresso. Este é que recebe deste Ato Institucional, resultante do Poder Constituinte inerente a todas as revoluções, a sua legitimação." 18 
Nos anos subsequentes a tendência a legitimação do governo pelo próprio uso do poder revolucionário levou ao fechamento do gradual do regime, que, com a edição do AI5 , passa a prescindir completamente do aval de setores da sociedade civil para o uso da coerção organizada.

Concomitantemente, o regime preocupou-se em legitimar-se positivamente, através da negação "do caos e da corrupção" da República Populista. A atuação neste sentido se deu especialmente no campo econômico, num processo de legitimação pela racionalidade e eficiência econômica. Configurava-se assim, segundo Lamounier, uma tentativa de legitimar-se pelo exercício do poder, e, por isso a preocupação na legalidade para justificar sua legitimidade, através dos Atos Institucionais, na manutenção do Congresso - embora somente com funções simbólicas - e a exigência de uma certa legitimidade democrática através de eleições (foi mantido o alistamento e um calendário eleitoral) indiretas para os cargos executivos. Esta preocupação com a legalidade teria atuado de forma positiva posteriormente, na transição para o governo civil. Por outro lado, ele vê no excessivo prolongamento do regime e em seu enrijecimento a partir de 1968 pontos negativos, que posteriormente fragilizariam o regime civil.

No campo econômico, o esforço inicial do primeiro governo militar foi o de reconstrução econômica. Neste campo específico se faz notar o grande poder assumido pelos tecnocratas durante o governo militar.

Auxiliados pela autonomia conferida pela concentração do poder em suas mãos, os militares centraram esforços na redução das taxas de inflação (política de estabilização) e na modernização e racionalização da economia. Numa segunda etapa buscou-se, dentro do processo de legitimação pela eficiência, a expansão econômica acelerada, onde o setor externo passou a exercer um papel fundamental no financiamento do crescimento da economia.

A estratégia econômica do Estado pós-64 baseavase no incremento do poder de intervenção do estatal na economia, que dispensava os equilíbrios de interesses da República Populista e possibilitou dessa forma uma maior autonomia do poder executivo para melhorar a máquina burocrática do Estado e incremento da capacidade de extração de recursos da sociedade.

Nesse panorama de fechamento político e alto índice de intervencionismo estatal na economia, o Conselho Monetário Nacional passou a exercer uma importante papel enquanto arena de discussão e negociação da política econômica do Governo:

\footnotetext{
"De fato, a coligação de tecnocratas e militares no poder, de 1964 a 1974, também tinha necessariamente facções e divergências, e a pergunta que caber fazer é: qual o local onde estas facções se acomodavam, compartilhando o poder? A minha hipótese é que os tecnocratas da área econômica, no sistema político brasileiro de 1964 a 1974, tiveram, sobretudo a partir de 1969, o seu locus de acomodação no Conselho Monetário Nacional."19
}

Nota-se, assim, que a teoria weberiana vem exercendo uma grande influência nas análises que tentam explicar as relações entre o Estado e a sociedade no Brasil. Pode-se perceber o quão marcante é esta influência simplesmente ao se perceber que está presente desde o primeiro quartel do século $\mathrm{XX}$ até os dias de hoje.

Sua influência representou um ponto de inflexão no desenvolvimento do pensamento político da sociedade brasileira; deslocando o debate acerca das questões de superioridade ou inferioridade étnica que marcavam o pensamento político do final do século XIX e início do século XX, marcadamente na obra de Oliveira Vianna - fruto certamente da herança escravista do Brasil — para a questão das origens profundas da sociedade brasileira, buscando na herança cultural e política as bases que a moldaram, como fica evidente nas obras de Sérgio Buarque de Holanda e Raymundo Faoro; abrindo caminho para o desenvolvimento de uma teoria democrática no Brasil.

\section{NOTAS}

1 In WEBER, M., 1991, p.139.

2 In op. cit., p.139.

${ }^{3}$ Em sua própria conceituação, Weber esclarece que o tipo ideal é apenas e tão somente uma construção teórica que visa sistematizar e possibilitar a compreensão de fenômenos que são parte de uma realidade muito complexa para ser apreendida diretamente e que, portanto, na realidade não são encontrados em seus tipos puros.

${ }^{4}$ Trabalhando as origens da formação cultural brasileira, Raymundo Faoro analisa também a sociedade brasileira a partir das origens portuguesas da cultura. Faoro vê a cultura portuguesa como resultado do encontro entre uma cultura latina e outra moura, conseqüência do contato prolongado que tiveram na Península Ibérica. A própria formação do Estado português está relacionada a este contato, visto que ela se dá no processo de expulsão dos mouros da península, dentro do contexto da Guerra de Reconquista.

${ }^{5}$ Faoro vê a centralização no Estado do papel de elemento de união nacional ligado às próprias origens do Estado português, cuja formação se dá no processo de expulsão dos mouros da península Ibérica, dentro do contexto da Guerra de Reconquista, o que deu origem a um. Estado centralizador e militarizado e de grande influência da religião católica.

${ }^{6}$ In op. cit., p. 9.

$?$ In op. cit., p. 41.

8 A denominação "Homem Cordial" não guarda nenhuma conotação, como enfatiza o autor, ética nos moldes da interpretação dada por Cassiano Ricardo, onde o termo assume o sentido de bondade, gentileza. Em nota da obra (p.107), Holanda esclarece que seu conceito de cordialidade liga-se a idéia de comportamento passional. A seguir reproduz-se trecho esclarecedor a este respeito: "Cumpre ainda acrescentar que essa cordialidade, estranha, por um lado, a todo formalismo e convencionalismo social, não abrange, por outro, apenas e obrigatoriamente, sentimentos positivos e de concórdia. A inimizade bem pode ser tão cordial como a amizade, nisto que uma e outra nascem do coração, procedem, assim, da esfera do íntimo, do familiar, do privado".

9 A esse respeito, ver "Coronelismo, enxada e voto", onde Victor Nunes Leal disseca a estrutura do compromisso coronelista e sua conexão com o Estado centralizado

${ }^{10} \mathrm{O}$ modus operandi coronelista, porém, consistia de uma extensa rede de interdependência que não se restringia a esta dependência econômica dos colonos em relação ao "coronel", que tinha por base a centralização financeira na esfera federal. Vide LEAL, V.N., "Coronelismo, enxada e voto".

${ }^{11}$ Deve-se lembrar que Weber identifica o tipo mais puro de dominação racional-legal com aquela exercida através de um quadro administrativo-burocrático, composto por funcionários, caracterizados segundo o autor por:

"1. São pessoalmente livres; obedecem somente às obrigações objetivas de seu cargo; 
2. são nomeados (e não eleitos) numa hierarquia rigorosa de cargos; 3. têm competências funcionais fixas;

4. em virtude de um contrato, portanto, (em princípio) sobre a base de livre seleção segundo

5. a qualificação profissional - no caso mais racional: qualificação verificada mediante prova e certificada por diploma;

6. são remunerados por salários fixos em dinheiro, na maioria dos casos com direito a aposentadoria; em certas circunstâncias (...) podem ser demitidos pelo patrão, porém sempre podem demitir-se por sua vez (...).

7. Exercem seu cargo como profissão única ou principal;

8. têm a perspectiva de uma carreira: 'progressão' por tempo de serviço ou eficiência, ou ambas as coisas, dependendo do critério dos superiores;

9. trabalham em 'separação absoluta dos meios administrativos' $e$ sem apropriação do cargo;

10. estão submetidos a um sistema rigoroso e homogêneo de disciplina e controle do serviço" (in WEBER, M., Economia e sociedade. Brasília: Editora UnB, 1994. p.144)

${ }^{12}$ Departamento Administrativo do Serviço Público. O DASP, criado em 1938 foi concebido, segundo Lawrence Graham, como uma organização técnica, ao qual os órgãos ministeriais se sujeitariam em relação a assuntos técnicos, mantendo-se sujeitos à hierarquia usual nos assuntos de administração geral. Porém, na prática, as atribuições do DASP foram muito além da simples atuação técnica.

${ }^{13}$ A autora observa, porém, que a construção de um Estado centralista, não significou a marginalidade dos setores hegemônicas durante a Primeira República, mas uma redefinição dos canais de influência, onde mecanismos jurídico - institucionais e políticos criados à partir de 30 passam a subordinar e ao mesmo tempo absorver as estruturas políticas regionais da Primeira República. Não houve, assim, uma reforma profunda na estrutura socioeconômica precedente à Revolução de 30 , mas sim um novo ordenamento político dos grupos de interesse novos e antigos, cooptados pela nova estrutura estatal e burocratizados.

${ }^{14}$ In op cit., p. 96.

${ }^{15}$ Lamounier defende a idéia de que o período getulista logrou lançar as bases do processo de instauração da democracia (pelo menos em seu caráter formal), através da formação de um espaço eleitoral (por paradoxal que possa parecer em um regime que em 1937 instauraria a ditadura do Estado Novo, mas que, por outro lado, rompeu com as práticas eleitorais da República Velha), do reconhecimento de mútua legitimidade entre os contendores, o que estabelece os limites da disputa dentro do âmbito da arena institucional (reconhecimento mútuo este rompido posteriormente, como se verá mais adiante) e da existência de uma aparelho estatal burocrático-coercitivo capaz de controlar o território e os confrontos entre as variadas vertentes políticas.

${ }^{16}$ A segunda perna do tripé getulista, que visava acomodar a complexidade política pré-existente ao recém instaurado Estado centralizado era o consociativismo, que começa se estruturar com a promulgação do código eleitoral de 1932 e consiste basicamente na garantia de representação das minorias políticas no Estado. A terceira perna do tripé era constituída pelo corporativismo sindical, com o qual se intentava regular os limites dos conflitos que surgem no âmbito do processo social.

${ }^{17}$ Sobre a dominação carismática, diz Weber: "Denominamos 'carisma' uma qualidade pessoal considerada extracotidiana (...) e em virtude da qual se atribuem a uma pessoa poderes ou qualidades sobrenaturais, sobre-humanos ou, pelo menos, extra-cotidianos específicos ou então se torna como enviada por Deus, como exemplar, e, portanto, como líder.(...). Sobre a validade do carisma decide o livre reconhecimento deste pelos dominados, consolidado em virtude de provas - originalmente, em virtude de milagres - e oriundo da entrega à revelação, da veneração de heróis ou da confiança no líder. Mas esse reconhecimento (...) não é a razão da legitimidade; constitui, antes, um dever das pessoas chamadas a reconhecer essa qualidade, em virtude de vocação e provas. Psicologicamente, esse 'reconhecimento' é uma entrega crente e inteiramente pessoal nascida do entusiasmo ou da miséria e esperança." (in WEBER, M., op. cit., pág. 158/159). Grifos nossos.

${ }^{18}$ In op. cit., p. 72.

${ }^{19}$ In op. cit., p. 90.

\section{BIBLIOGRAFIA}

BARBOSA, Maria Lúcia Victor. América Latina - em busca do paraíso perdido. São Paulo: Saraiva, 1995.

FAORO, Raymundo. Existe um pensamento político brasileiro? São Paulo: Ática, 1994

Os donos do poder. Rio de Janeiro: Globo, 1989.

HOLANDA, Sérgio Buarque de. Raizes do Brasil. São Paulo: Cia. das Letras, 1995.

LAFER, Celso. O sistema político brasileiro. São Paulo: Perspectiva, 1975.

LAMOUNIER, Bolivar. "E no entanto se move: formação e evolução do Estado". In: LAMOUNIER, B.; CARNEIRO, D. (org.) Cinqüenta anos de Brasil. Rio de Janeiro: Editora da Fundação Getúlio Vargas, 1994.

A democracia brasileira no limiar do século 21.São Paulo Fundação Konrad-Adenauer-Stiftung, 1996.

REZENDE, Maria José de. "Democracia em Gilberto Freire e Sérgio Buarque de Holanda". Plural (Sociologia). USP, São Paulo, n.3, pp. 14-48, 1 sem. 1996.

SOUZA, Maria do Carmo Campello de. Estado e partidos políticos no Brasil. São Paulo. Editora Alfa-Ômega, 1976.

WEBER, Max. Ciência e política - Duas vocações. São Paulo: Cultrix, 1998

Economia e Sociedade. Brasília: UNB, 1994. 